\title{
Is There a Prima Facie Obligation to Obey the Law?*
}

\author{
M. B. E. Smith†
}

It isn't a question of whether it was legal or illegal. That isn't enough. The question is, what is morally wrong.

-Richard Nixon, "Checkers Speech" 1952.

Many political philosophers have thought it obvious that there is a prima facie obligation to obey the law; and so, in discussing this obligation, they have thought their task to be more that of explaining its basis than of arguing for its existence. John Rawls has, for example, written:

I shall assume, as requiring no argument, that there is, at least in a society such as ours, a moral obligation to obey the law, although it may, of course, be overriden in certain cases by other more stringent obligations. ${ }^{1}$

As against this, I suggest that it is not at all obvious that there is such an obligation, that this is something that must be shown, rather than so blithely assumed. Indeed, were he uninfluenced by conventional wisdom, a reflective man might on first considering the question be inclined to deny any such obligation: As H. A. Prichard once remarked, "the mere receipt of an order backed by force seems, if anything, to give rise to the duty of resisting, rather than obeying."'

I shall argue that, although those subject to a government often have a prima facie obligation to obey particular laws (e.g., when disobedience has seriously untoward consequences or involves an act that is mala in se), they have no prima facie obligation to obey all its laws. I do not hope to prove this contention beyond a reasonable doubt: My goal is rather the more modest one of showing that it is a reasonable position to maintain by first criticizing arguments that purport

* Assistant Professor of Philosophy, Smith College.

$\dagger$ I wish to thank Judith Jarvis Thomson, Hugo A. Bedau, Gerald Barnes, Murray Kiteley, Robert Ackermann, and Stanley Rothman, for their criticism of earlicr drafts of this article.

1. Rawls, Legal Obligation and the Duty of Fair Play, in LAW AND PHitcosonuY 3 (S. Hook ed. 1964).

2. H.A. Prichard, Green's Principles of Political Obligation, in Moral Oulication 54 (1949). 
to establish the obligation and then presenting some positive argument against it.

First, however, I must explain how I use the phrase "prima facic obligation." I shall say that a person $S$ has a prima facie obligation to do an act $X$ if, and only if, there is a moral reason for $S$ to do $X$ which is such that, unless he has a moral reason not to do $X$ at least as strong as his reason to do $X, S$ 's failure to do $X$ is wrong. ${ }^{3}$ In this discussion it will also be convenient to distinguish two kinds of prima facic obligation via the difference between the two kinds of statement which ascribe them. A specific statement asserts that some particular person has a prima facie obligation to perform some particular act. In contrast, a generic statement (e.g., "Parents have a prima facic obligation to care for their infant children") asserts that everyone who meets a certain description has a prima facie obligation to perform a certain kind of act whenever he has an opportunity to do so. I shall therefore say that a person $S$ has a specific prima facie obligation to do $\mathrm{X}$ if, and only if, the specific statement " $S$ has a prima facie obligation to do $X$ " is true; and that he has a generic prima facie obligation to do $X$ if, and only if, $S$ meets some description $\mathrm{D}$ and the generic statement "Those who are $\mathrm{D}$ have a prima facie obligation to do $\mathrm{X}$ " is true."

Now, the question of whether there is a prima facie obligation to obey the law is clearly about a generic obligation. Everyone, even the anarchist, would agree that in many circumstances individuals have specific prima facie obligations to obey specific laws. Since it is clear that there is in most circumstances a specific prima facie obligation to refrain from murder, rape, or breach of contract, it is plain that in these circumstances each of us has a specific prima facie obligation not to violate laws which prohibit these acts. Again, disobeying the law often has seriously untorvard consequences; and, when this is so, virtually everyone would agree that there is a specific prima facie obligation to obey. Therefore, the interesting question about our obligation vis-à-vis the law is not "Do individual citizens ever have specific prima

3. The distinction between prima facie and absolute obligation was first made by W.D. Ross in THE RIGHT AND THE Good ch. 2 (1930). MIy account of prima facie obligation differs somewhat from Ross'; but I believe it adequately captures current philosophical usage. As for absolute obligation, I shall not often speak of it; but when I do, what I shall mean by " $S$ has an absolute obligation to do $x$ " is that " $S$ 's failure to do $X$ is wrong."

4. My motive for distinguishing generic and specific prima facic obligations is simply convenience, and not because I think it provides a perspicuous way of classifying prima facie obligations. As a classification it is obviously defective: The two kinds of obliga. tion overlap, since in a trivial sense every specific obligation can be construed as a generic one; and there are some prima facie obligations (c.g., the obligation to keep one's promise), that fit neither definition. 
facie obligations to obey particular laws?," but rather "Is the moral relation of any government to its citizens such that they have a prima facie obligation to do certain things merely because they are legally required to do so?" This is, of course, equivalent to asking "Is there a generic prima facie obligation to obey the law?" Hereafter, when I use the phrase "the prima facie obligation to obey the law" I shall be referring to a generic obligation.

One final point in clarification: As used here, the phrase "prima facie" bears a different meaning than it does when used in legal writing. In legal materials, the phrase frequently refers to evidence sufficiently persuasive so as to require rebuttal. Hence, were a lawyer to ask "Is there a prima facie obligation to obey the law?," a reasonable interpretation of his question might be "May a reasonable man take mere illegality to be sufficient evidence that an act is morally wrong, so long as there is no specific evidence tending to show it is right?" Let us call this the "lawyer's question." Now, the question of primary concern in this inquiry is "Is there any society in which mere illegality is a moral reason for an act's being wrong?" The difference between these questions is that, were there a prima facie obligation to obey the law in the lawyer's sense, mere illegality would, in the absence of specific evidence to the contrary, be evidence of wrongdoing, but it would not necessarily be relevant to a determination of whether lawbreaking is wrong where there is reason to think such conduct justified or even absolutely obligatory. In contrast, if there is a prima facie obligation to obey the law in the sense in which I am using the phrase, the mere illegality of an act is always relevant to the determination of its moral character, despite whatever other reasons are present. ${ }^{5}$ Hence, there may be a prima facie obligation to obey the law in the lawyer's sense and yet be no such obligation in the sense of the phrase used here. Near the end of this article I shall return briefly to the lawyer's question; for the present, $I$ raise it only that it may not be confused with the question I wish to examine.

5. An example may help to make the point clear. If I promise that I will mect someone at a certain time, I have a prima facie obligation to kecp my promise. Now, were this merely a prima facie obligation in the lawyer's sense, without evidence to the con* trary the fact that $I$ had promised would be sufficient to hold that a breach of my promise was wrong, yet it would not be evidence of wrongdoing were there reason to believe the breach was justified or even obligatory. But, in fact, this is not what we think of promising. We think that if someone promises to do a thing there is a strong moral reason for him to do it and that, although this reason may sometimes be op. posed by stronger reasons to the contrary, its weight does not disappear. In such cases, my promise is yet relevant to what $I$ am absolutely obligated to do, although it is not always determinative. But, even when this reason is outweighed, it still discloses its existence by imposing fresh prima facie obligations (e.g., to tell the person I promiscd why I broke it). Hence, there is a prima facie obligation to keep one's promisc in the sense in which $I$ here use the phrase. 
The arguments I shall examine fall into three groups: First, those which rest on the benefits each individual receives from government; second, those relying on implicit consent or promise; third, those which appeal to utility or the general good. I shall consider each group in turn.

Of those in the first group, I shall begin with the argument from gratitude. Although they differ greatly in the amount of benefits they provide, virtually all governments do confer substantial benefits on their subjects. Now, it is often claimed that, when a person accepts benefits from another, he thereby incurs a debt of gratitude towards his benefactor. Thus, if it be maintained that obedience to the law is the best way of showing gratitude towards one's government, it may with some plausibility be concluded that each person who has received benefits from his government has a prima facie obligation to obey the law.

On reflection, however, this argument is unconvincing. First, it may reasonably be doubted whether most citizens have an obligation to act gratefully towards their government. Ordinarily, if someone confers benefits on me without any consideration of whether I want them, and if he does this in order to advance some purpose other than promotion of my particular welfare, I have no obligation to be grateful towards him. Yet the most important benefits of government are not accepted by its citizens, but are rather enjoyed regardless of whether they are wanted. Moreover, a government typically confers these benefits, not to advance the interests of particular citizens, but rather as a consequence of advancing some purpose of its own. At times, its motives are wholly admirable, as when it seeks to promote the general welfare; at others, they are less so, as when it seeks to stay in power by catering to the demands of some powerful faction. But, such motives are irrelevant: Whenever government forces benefits on me for reasons other than my particular welfare, I clearly am under no obligation to be grateful to it.

Second, even assuming arguendo that each citizen has an obligation to be grateful to his government, the argument still falters. It is perhaps true that cheerful and willing obedience is the best way to show one's gratitude towards government, in that it makes his gratitude unmistakable. But, when a person owes a debt of gratitude towards another, he does not necessarily acquire a prima facie obligation to display his gratitude in the most convincing manner: A person with demanding, domineering parents might best display his gratitude towards them by catering to their every whim, but he surely has no 
prima facie obligation to do so. Without undertaking a lengthy case-bycase examination, one cannot delimit the prima facie obligation of acting gratefully, for its existence and extent depends on such factors as the nature of the benefits received, the manner in which they are conferred, the motives of the benefactor, and so forth. But, even without such an examination, it is clear that the mere fact that a person has conferred on me even the most momentous benefits does not establish his right to dictate all of my behavior; nor does it establish that I always have an obligation to consider his wishes when I am deciding what I shall do. If, then, we have a prima facie obligation to act gratefully towards government, we undoubtedly have an obligation to promote its interests when this does not involve great sacrifice on our part and to respect some of its wishes concerning that part of our behavior which does not directly affect its interests. But, our having this obligation to be grateful surely does not establish that we have a prima facie obligation to obey the law.

A more interesting argument from the benefits individuals receive from government is the argument from fair play. It differs from the argument from gratitude in contending that the prima facia obligation to obey the law is owed, not to one's government but rather to one's fellow citizens. Versions of this argument have been offered by H. L. A. Hart and John Rawls.

According to Hart, the mere existence of cooperative enterprise gives rise to a certain prima facie obligation. He argues that:

when a number of persons conduct any joint enterprise according to rules and thus restrict their liberty, those who have submitted to these restrictions when required have a right to a similar submission from those who have benefitted by their submission. The rules may provide that officials should have authority to enforce obedience and make further rules, and this will create a structure of legal rights and duties, but the moral obligation to obey the rules in such circumstances is due to the cooperating members of the society, and they have the correlative moral right to obedience. ${ }^{6}$

Rawls' account of this obligation in his essay, Legal Obligation and the Duty of Fair Play, ${ }^{7}$ is rather more complex. Unlike Hart, he sets cer-

b. Hart, Are There Any Natural Rights?, 64 PHIL. Rev. 185 (1955). I must note that Hart does not use the phrase "prima facie obligation," maintaining that his argument establishes an obligation sans phrase to comply with the rules of cooperative enterprises. However, since his use of "obligation" seems much the same as my use of "prima facic obligation," I shall ignore his terminological scruples.

7. Rawls, supra note 1 . The same argument appears, although in less dctail, in Rawls, Justice as Fairness, 67 PHIL. REv. 164 (1958), and Rawls, The Justification of Civil Disobedience, in Civil Disobedience: Theory and Practice (H.A. Bedau ed. 1969). 
tain requirements on the kinds of cooperative enterprises that give rise to the obligation: First, that success of the enterprise depends on nearuniversal obedience to its rules, but not on universal cooperation; second, that obedience to its rules involves some sacrifice, in that obeying the rules restricts one's liberty; and finally, that the enterprise conform to the principles of justice. ${ }^{8}$ Rawls also offers an explanation of the obligation: $\mathrm{He}$ argues that, if a person benefits from participating in such an enterprise and if he intends to continue receiving its benefits, he acts unfairly when he refuses to obey its rules. With Hart, however, Rawls claims that this obligation is owed not to the enterprise itself, nor to its officials, but rather to those members whose obedience has made the benefits possible. Hart and Rawls also agree that this obligation of fair play-“fair play" is Rawls' term-is a fundamental obligation, not derived from utility or from mutual promise or consent. ${ }^{\circ}$ Finally, both Hart and Rawls conceive of legal systems, at least those in democratic societies, as complex practices of the kind which give rise to the obligation of fair play; and they conclude that those who benefit from such legal systems have a prima facie obligation to obey their laws.

These arguments deserve great respect. Hart and Rawls appear to have isolated a kind of prima facie obligation overlooked by other philosophers and have thereby made a significant contribution to moral theory. However, the significance of their discovery to jurisprudence is less clear. Although Hart and Rawls have discovered the obligation of fair play, they do not properly appreciate its limits. Once these limits are understood, it is clear that the prima facie obligation to obey the law cannot be derived from the duty of fair play.

The obligation of fair play seems to arise most clearly within small, voluntary cooperative enterprises. Let us suppose that a number of persons have gone off into the wilderness to carve out a new society, and that they have adopted certain rules to govern their communal life. Their enterprise meets Rawls' requirements on success, sacrifice, and justice. We can now examine the moral situation of the members of that community in a number of circumstances, taking seriously Hart's insistence that cooperating members have a right to the obedience of

8. Rawls, Legal Obligation and the Duty of Fair Play, in LAw axd Punosom 10 (S. Hook ed. 1964). According to Rawls, the principles of justice are that everyone have an equal right to the most extensive liberty compatible with a like liberty for all; ... [and] that inequalities are arbitrary unless it is reasonable to expect that they will work out for ereryone's advantage and provided that the positions and offices to which they attached or from which they may be gained are open to all.

Id. at 11 .

9. Id. at 13; Hart, supra note 6, at 185. 
others and Rawls' explanation of this right and its correlative obligation on grounds of fairness.

Let us take two members of the community, $A$ and $B$. $B$, we may suppose, has never disobeyed the rules, and $A$ has benefitted from $B$ 's previous submission. Has $B$ a right to $A$ 's obedience? It would seem necessary to know the consequences of $A$ 's obedience. If, in obeying the rules, $A$ will confer on $B$ a benefit roughly equal to those he has received from $B$, it would be plainly unfair for $A$ to withhold it from $B$; and so, in this instance, $B$ 's right to $A$ 's obedience is clear. Similarly, if, in disobeying the rule, $A$ will harm the community, $B$ 's right to $A$ 's obedience is again clear. This is because in harming the community $A$ will harm $B$ indirectly, by threatening the existence or efficient functioning of an institution on which $B$ 's vital interests depend. Since $A$ has benefitted from $B$ 's previous submission to the rules, it is unfair for $A$ to do something which will lessen $B$ 's chances of receiving like benefits in the future. However, if $A$ 's compliance with some particular rule does not benefit $B$ and if his disobedience will not harm the community, it is difficult to see how fairness to $B$ could dictate that $A$ must comply. Surely, the fact that $A$ has benefitted from $B$ 's submission does not give $B$ the right to insist that $A$ obey when $B$ 's interests are unaffected. $A$ may in this situation have an obligation to obey, perhaps because he has promised or because his disobedience would be unfair to some other member; but, if he does disobey, he has surely not been unfair to $B$.

We may generalize from these examples. Considerations of fairness apparently do show that, when cooperation is perfect and when each member has benefitted from the submission of every other, each mem. ber of an enterprise has a prima facie obligation to obey its rules when obedience benefits some other member or when disobedience harms the enterprise. For, if in either circumstance a member disobeys, he is unfair to at least one other member and is perhaps unfair to them all. However, if a member disobeys when his obedience would have benefitted no other member and when his disobedience does no harm, his moral situation is surely different. If his disobedience is then unfair, it must be unfair to the group but not to any particular member. But this, I take it, is impossible: Although the moral properties of a group are not always a simple function of the moral properties of its members, it is evident that one cannot be unfair to a group without being unfair to any of its members. It would seem, then, that even when cooperation is perfect, considerations of fairness do not establish that members of a cooperative enterprise have a simple obligation to obey 
all of its rules; but have rather the more complex obligation to obey when obedience benefits some other member or when disobedience harms the enterprise. This does not; it is worth noting, reduce the obligation of fair play to a kind of utilitarian obligation, for it may well be that fair play will dictate in certain circumstances that a man obey when disobedience would have better consequences. My point is merely that the obligation of fair play governs a man's actions only when some benefit or harm turns on whether he obeys. Surely, this is as should be, for questions of fairness typically arise from situations in which burdens or benefits are distributed or in which some harm is done.

The obligation of fair play is therefore much more complex than Hart or Rawls seem to have imagined. Indeed, the obligation is even more complex than the above discussion suggests, for the assumption of perfect cooperation is obviously unrealistic. When that assumption is abandoned, the effect of previous disobedience considered, and the inevitable disparity among the various members' sacrifice in obeying the rules taken into account, the scope of the obligation is still further limited; we shall then find that it requires different things of different members, depending on their previous pattern of compliance and the amount of sacrifice they have made. ${ }^{10}$ These complications need not detain us, however, for they do not affect the fact that fairness requires obedience only in situations where noncompliance would withhold benefits from someone or harm the enterprise. Now it must be conceded that all of this makes little difference when we confine our attention to small, voluntary, cooperative enterprises. Virtually any disobedience may be expected to harm such enterprises to some extent, by diminishing the confidence of other members in its probable success and therefore reducing their incentive to work diligently towards it. Moreover, since they are typically governed by a relatively small

10. Those intrigued by the mention of these additional factors may be interested to know that, when imperfect cooperation is taken into account, it can be shown that considerations of fairness establish no more than: (1) that a member $A$ of a cooperative enterprise has a prima facie obligation to obey when his obedience vill bencfit some other member $B$ from whose submission $A$ has previously benefitted and it is not the case that $B$ has withheld from $A$ more significant benefits than $A$ withholds from $B$; and (2) that $A$ has a prima facie obligation to obey when his disobedience harms the enterprise and there is some other member $B$ from whose submission $A$ has previously benefitted and $B$ has by his disobedience harmed the enterprise less than the harm which would be done by $A$ 's disobedience.

As for the effect of disparity in sacrifice, it was only recently suggested to me that this factor must be taken into account, and I have not yet attempted to determine its effects precisely. A moment's reflection discloses, however, that this additional factor would make the obligation still more complex. Were anyone to attempt a precise specification of the citizen's obligations vis-a-vis the laws of his government, he would have to master these complexities; but my task is not so ambitious. 
number of rules, none of which ordinarily require behavior that is useless to other members, we may expect that when a member disobeys he will probably withhold a benefit from some other member and that he has in the past benefitted significantly from that member's obedience. We may therefore expect that virtually every time the rules of a small, voluntary enterprise call on a member to obey he will have a specific prima facie obligation to do so because of his obligation of fair play.

In the case of legal systems, however, the complexity of the obligation makes a great deal of difference. Although their success may depend on the "habit of obedience" of a majority of their subjects, all legal systems are designed to cope with a substantial amount of disobedience. ${ }^{11}$ Hence, individual acts of disobedience to the law only rarely have an untoward effect on legal systems. What is more, because laws must necessarily be designed to cover large numbers of cases, obedience to the law often benefits no one. Perhaps the best illustration is obedience of the traffic code: Very often I benefit no one when I stop at a red light or observe the speed limit. Finally, virtually every legal system contains a number of pointless or even positively harmful laws, obedience to which either benefits no one or, worse still, causes harm. Laws prohibiting homosexual activity or the dissemination of birth control information are surely in this category. Hence, even if legal systems are the kind of cooperative enterprise that gives rise to the obligation of fair play, in a great many instances that obligation will not require that we obey specific laws. If, then, there is a generic prima facie obligation to obey the laws of any legal system, it cannot rest on the obligation of fair play. The plausibility of supposing that it does depends on an unwarranted extrapolation from what is largely true of our obligations within small, cooperative enterprises to what must always be true of our obligations within legal systems.

In his recent book, Rawls has abandoned the argument from fair play as proof that the entire citizenry of even just governments has a prima facie obligation to obey the law. He now distinguishes between obligations (e.g., to be fair or to keep promises) and natural duties (e.g., to avoid injury to others). Obligations, according to Rawls, are incurred only by one's voluntary acts, whereas this is not true of natu-

11. Indeed, it seems strange that Rawls should have attempted to base the prina facie obligation to obey the law on fair play, since he maintains that this latter obligation is incurred within cooperative enterprises that depend on near-universal cooperation. Rawls, Legal Obligation and the Duty of Fair Play, in LAW AND Prilosoprix 10 (S. Hook ed. 1964). 
ral duties. ${ }^{12}$ In his book, he retains the obligation of fair play (now "fairness"); but he now thinks that this obligation applies only to those citizens of just governments who hold office or who have advanced their interests through the government. He excludes the bulk of the citizenry from having a prima facie obligation to obey the law on the ground that, for most persons, receiving benefits from government is nothing they do voluntarily, but is rather something that merely happens to them. ${ }^{13}$ He does not, however, take this to imply that most citizens of a reasonably just government are morally free to disobey the law: He maintains that everyone who is treated by such a government with reasonable justice has a natural duty to obey all laws that are not grossly unjust, on the ground that everyone has a natural duty to up. hold and to comply with just institutions. ${ }^{1+}$

It is tempting to criticize Rawls' present position in much the same way that I criticized his earlier one. One might argue that, while it is true that officeholders and those who have profited by invoking the rules of a just government must in fairness comply with its laws when disobedience will result in harm to that government or when it withholds a benefit from some person who has a right to it, it is simply false that fairness dictates obedience when disobedience does no harm or withholds no benefit. One might further argue that the utility of a just government is such that one has a prima facie duty to obey when disobedience is harmful to it, but that, so long as disobedience does no harm, the government's character is irrelevant to the question of whether one has a prima facie obligation to obey. These criticisms would, I think, show that if we are to base our normative ethics on an appeal to intuitively reasonable principles of duty and obligation, Rawls' present position is no more satifying than is his earlier one. However, although certainly relevant to an assessment of Rawls' present position, these arguments cannot be regarded as decisive, for in his book Rawls does not rely on a bare appeal to moral intuition. He does not disregard the evidence of intuition, and he is glad to enlist its aid when he can; but, in putting forward particular principles of duty and obligation, he is more concerned with showing that they follow from his general theory of justice. Hence, to refute Rawls' present position, one would have to set out his elaborate theory and then show either that it is mistaken or that the particular claims he makes on its basis do not follow from it. Such a task is beyond the scope of this

12. J. Rawls, A Theory of Justice 108 (1971).

13. Id. at 336,344 .

14. Id. at $334-37,350-62$. 
article; and I shall therefore be content to observe that Rawls' present position lacks intuitive support and, hence, that it rests solely on a controversial ethical theory and a complicated argument based upon it, neither of which have as yet emerged unscathed from the fire of critical scrutiny. His view deserves great respect and demands extended discussion, but it is not one which we must now accept, on pain of being unreasonable.

\section{II}

The second group of arguments are those from implicit consent or promise. Recognizing that among the clearest cases of prima facie obligation are those in which a person voluntarily assumes the obligation, some philosophers have attempted to found the citizen's obligation to obey the law upon his consent or promise to do so. There is, of course, a substantial difficulty in any such attempt, viz., the brute fact that many persons have never so agreed. To accommodate this fact, some philosophers have invoked the concept of implicit promise or consent. In the Second Treatise, Locke argued that mere residence in a country, whether for an hour or a lifetime, constitutes implicit consent to its law. ${ }^{15}$ Plato $^{16}$ and W. D. Ross ${ }^{17}$ made the similar argument that residence in a country and appeal to the protection of its laws constitutes an implicit promise to obey.

Nevertheless, it is clear that residence and use of the protection of the law do not constitute any usual kind of consent to a government nor any usual kind of promise to obey its laws. The phrases "implicit consent" and "implicit promise" are somewhat difficult to understand, for they are not commonly used; nor do Locke, Plato, or Ross define them. Still, a natural way of understanding them is to assume that they refer to acts which differ from explicit consent or promise only in that, in the latter cases, the person has said "I consent ..." or "I promise ..." "whereas in the former, he has not uttered such words but has rather performed some act which counts as giving consent or making a promise. Now, as recent investigation in the philosophy of language has shown, certain speech acts are performed only when some. one utters certain words (or performs some other conventional act) with the intention that others will take what he did as being an instance of the particular act in question. ${ }^{18}$ And it is certain that, in their ordinary

15. J. Locke, Two Treatises of Government Bk. II, I 119 (1690).

16. I Plato, Dialogues 435 (B. Jowett transl. 1892).

17. Ross, supra note 3 , at 27.

18. Cf. Strawson, Intention and Convention in Speech Acts, 73 Pult. Rev. 439, 448.49, 457.59 (1964). 
usage, "consenting" and "promising" refer to speech acts of this kind. If I say to someone, "I promise to give you fifty dollars," but it is clear from the context that I do not intend that others will take my utterance as a promise, no one would consider me as having promised. Bringing this observation to bear on the present argument, it is perhaps possible that some people reside in a country and appeal to the protection of its laws with the intention that others will take their residence and appeal as consent to the laws or as a promise to obey; but this is surely true only of a very small number, consisting entirely of those enamoured with social contract theory. ${ }^{10}$

It may be argued, however, that my criticism rests on an unduly narrow reading of the words "consent" and "promise." Hence, it may be supposed that, if I am to refute the implicit consent or promise arguments, I must show that there is no other sense of the words "consent" or "promise" in which it is true that citizens, merely by living in a state and going about their usual business, thereby consent or promise to obey the law. This objection is difficult to meet, for I know of no way to show that there is no sense of either word that is suitable for contractarian purposes. However, I can show that two recent attempts, by John Plamenatz and Alan Gewirth, to refurbish the implicit consent argument along this line have been unsuccessful. ${ }^{20}$ I shall not quarrel with their analyses of "consent," though I am suspicious of them; rather, I shall argue that given their definitions of "consent" the fact that a man consents to government does not establish that he has a prima facie obligation to obey the law.

Plamenatz claims that there are two kinds of consent. The first, which is common-garden variety consent, he terms "direct." He concedes that few citizens directly consent to their government."1 He suggests, however, that there is another kind of consent, which he calls "indirect," and that, in democratic societies, consent in this sense is widespread and establishes a prima facie obligation to obey the law.

19. A similar argument could also be made utilizing the analysis of promising in $J$. SeARLe, SPFech Acts: An Essay in the Philosophy of LANGuAGe 60 (1969).

20. Another recent tacit consent theory is found in J. TUSsMaN, OuLuastiox AND TIE: BoDy Polrric (1960). I shall not discuss this theory, however, because it has already received adequate criticism in Pitkin, Obligation and Consenl I, 59 AM. Pot. Scr. REv. 990 (1965). Nor shall I discuss Pitkin's own "hypothetical consent" theory that obedience is owed to those governments to which one ought to consent, because in her discussion of how political obligation is justified she does not appeal to the concept of hypothetial consent. She takes the problem of justifying political obligation to be the question "Why" am I ever obligated to obey even legitimate authority: She gives the question short shrift, however, replying that it is simply part of the meaning of the phrase "legitimate authority" that those subject to legitimate authority have a prima facic obligation to obey it. See Pitkin, Obligation and Consent II, 60 Asr. POL. Scr. REv. 39, 45-49 (1960).

21. J. Plamenatz, May and Society 228, 238-39 (1963). 
Indirect consent occurs whenever a person freely votes or abstains from voting. ${ }^{22}$ Voting establishes a prima facie obligation of obedience because:

Even if you dislike the system and wish to change it, you put yourself by your vote under a [prima facie] obligation to obey whatever government comes legally to power.... For the purpose of an election is to give authority to the people who win it and, if you vote knowing what you are doing and without being compelled to do it, you voluntarily take part in a process which gives authority to these people. ${ }^{23}$

Plamenatz does not explain why abstention results in a prima facie obligation, but perhaps his idea is that, if a person abstains, he in effect acknowledges the authority of whoever happens to win.

The key premise then in the argument is that "the purpose of an election is to give authority to the people who win it," and it is clear that Plamenatz believes that this implies that elections do give authority to their winners. In assessing the truth of these contentions, it is, of course, vital to know what Plamenatz means by "authority." Unfortunately, he does not enlighten us, and we must therefore speculate as to his meaning. To begin, the word "authority," when used without qualification, is often held to mean the same as "legitimate authority." Since prima facie obligation is the weakest kind of obligation, part of what we mean when we ascribe authority to some government is that those subject to it have at least a prima facie obligation to obey. However, if this is what Plamenatz means by "authority," his argument simply begs the question: For, in order to be justified in asserting that the purpose of an election is to confer authority and that elections succeed in doing this, he must first show that everyone subject to an elected government has a prima facie obligation to obey its law, both those eligible to vote and those ineligible.

It is possible, however, that Plamenatz is using "authority" in some weaker sense, one that does not entail that everyone subject to it has a prima facie obligation to obey. If this is so, his premises will perhaps pass, but he must then show that those who are eligible to take part in conferring authority have a prima facie obligation to obey it. However, it is difficult to see how this can be done. First, as Plamenatz recognizes, voting is not necessarily consenting in the "direct" or usual sense, and merely being eligible to vote is even more clearly not con-

22. Id. at $239-40$.

23. Id. 
senting. Hence, the alleged prima facie obligation of obedience incurred by those eligible to vote is not in consequence of their direct consent. Second, Plamenatz cannot appeal to "common moral sentiment" to bolster his argument: This is because if we really believed that those eligible to vote have a prima facie obligation to obey, an obligation not incurred by the ineligible, we should then believe that the eligible have a stronger obligation than those who are ineligible. But, as far as I can tell, we do not ordinarily think that this is true. Finally, Plamenatz cannot rely on a purely conceptual argument to make his point. It is by no means an analytic truth that those subject to elected governments have a prima facie obligation to obey the law. ${ }^{24}$ The radical who says, "The present government of the United States was freely elected, but because it exploits people its citizens have no obligation to obey it," has perhaps said something false, but he has not contradicted himself. Plamenatz's argument is therefore either question-begging or inconclusive, depending on what he means by "authority."

Gewirth's argument is similar to Plamenatz's in that he also holds that a person's vote establishes his prima facie obligation of obedience. $\mathrm{He}$ argues that men consent to government when "certain institutional arrangements exist in the community as a whole," including "the maintenance of a method which leaves open to every sane, noncriminal adult the opportunity to discuss, criticize, and vote for or against the government." ${ }^{25} \mathrm{He}$ holds that the existence of such consent "justifies" government and establishes the subject's prima facie obligation to obey because:

The method of consent combines and safeguards the joint values of freedom and order as no other method does. It provides a choice in the power of government which protects the rights of the electorate more effectively than does any other method. It does more

24. A defender of Plamenatz, John Jenkins, appears to hold that something like this is an analytic truth, maintaining that:

if a person supposes that he has no obligation to a successful candidate because that candidate happens not to be the person for whom he cast his vote, then there is an excellent case for saying that the man has failed to understand the nature of the electoral process.

Jenkins, Political Consent, 20 PHIL. Q. 61 (1970).

This seems a silly claim. Many who voted for Gcorge MrcGovern belicve themselves to be under no obligation to Richard Nixon. Some are highly educated and close ob. servers of the political scene. Were such a person to explain his belief that he is not obligated to Nixon solely on the ground that he did not vote for him, we might think him mistaken or wish that he had chosen a better reason, but we should have no reason at all to think that he fails to understand "the nature of the clectoral process."

25. Earlier in his discussion Gewirth distinguishes three senses of "consent": an "occurrence" sense, a "dispositional" sense, and an "opportunity" scnse. Id. at I31. It is only the last that will concern us here, since he admits that the prima facie obligation to obey the law cannot be shown by relying on the occurrence or the dispositional senses. Gewirth, Political Justice, in Social Justice 138 (R. Brandt cd. 1962). 
justice to man's potential rationality than does any other method, for it gives all men the opportunity to participate in a reasoned discussion of the problem of society and to make their discussion effective in terms of political control. ${ }^{26}$

As it stands, Gewirth's argument is incomplete. He makes certain claims about the benefits of government by consent which are open to reasonable doubt. Some communists, for example, would hold that Gewirth's method of consent has led to exploitation, and that human rights and freedom are better protected by the rule of the party. This aside, Gewirth's argument still needs strengthening. The fact that certain benefits are given only by government with a method of consent establishes only that such a government is better than one which lacks such a method. But, to show that one government is better than another, or even to show that it is the best possible government, does not prove that its subjects have a prima facie obligation to obey its laws: There is a prior question, which remains to be settled, as to whether there can be a prima facie obligation to obey any government. Gewirth does not carry the argument farther in his discussion of "consent," but earlier in his paper he hints as to how he would meet this objection. $\mathrm{He}$ argues that "government as such" is justified, or made legitimate, by its 'being necessary to avoid certain evils. ${ }^{27}$ Indeed, although he does not explicitly so state, he seems to think that utilitarian considerations demonstrate that there is a prima facie obligation to obey any government that protects its subjects from these evils, but that there is an additional prima facie obligation to obey a government with a method of consent because of the more extensive benefits it offers. In the next section, I shall discuss whether a direct appeal to utility can establish a prima facie obligation to obey the law.

\section{III}

I shall consider three utilitarian arguments: the first appealing to a weak form of act-utilitarianism, the second and third to rule-utilitarian theories. To my knowledge, the first argument has never been explicitly advanced. It is nevertheless worth considering, both because it possesses a certain plausibility and because it has often been hinted at when philosophers, lawyers, and political theorists have attempted to derive an obligation to obey the law from the premise that government

26. Id. at 139 .

27. Id. at 135 . 
is necessary to protect society from great evil. The argument runs as follows:

There is obviously a prima facie obligation to perform acts which have good consequences. Now, government is absolutely necessary for securing the general good: The alternative is the state of nature in which everyone is miserable, in which life is "solitary, poor, nasty, brutish and short." But, no government can long stand in the face of widespread disobedience, and government can therefore promote the general good only so long as its laws are obeyed. Therefore, obedience to the law supports the continued existence of government and, hence, always has good consequences. From this it follows that there is a prima facie obligation to obey the law.

On even brief scrutiny, however, this argument quickly disintegrates. The first thing to be noticed is that its principle of prima facie obligation is ambiguous. It may be interpreted as postulating either (a) an obligation to perform those acts which have any good consequences, or (b) an obligation to perform optimific acts (i.e., those whose consequences are better than their alternatives). Now, (a) and (b) are in fact very different principles. The former is obviously absurd. It implies, for example, that I have a prima facie obligation to kill whomever I meet, since this would have the good consequence of helping to reduce overpopulation. Thus, the only weak act-utilitarian principle with any plausibility is (b). But, regardless of whether (b) is acceptable-and some philosophers would not accept $\mathrm{it}^{28}$-the conclusion that there is a prima facie obligation to obey the law, cannot be derived from it, inasmuch as there are obvious and familiar cases in which breach of a particular law has better consequences than obedience. The only conclusion to be derived from (b) is that there is a specific prima facie obligation to obey the law whenever obedience is optimific. But no generic prima facie obligation to obey can be derived from weak actutilitarianism. ${ }^{29}$

28. For example, some philosophers would hold that there is a prima facie obligation to refrain from acts which have undesirable consequences, but not that there is an obligation to perform the one act which has the best consequences. Sec, C.g., M.G. Singer, Generalization in Etrics, ch. 7 (1961).

29. For purposes of clarification, I should emphasize that I am here concerned with act utilitarianism as a theory of prima facie, not absolutc, obligation. There is no incongruity here. The consequences of acts count as having great moral significance on virtually every moral theory; and so, one need not be a strict act utilitarian in order to maintain the principle that there is a prima facic obligation to act optimifically. Indeed, for a strict act utilitarian such as Bentham, it is pointless to vorry about whether there is a prima facie obligation to obey the law: He vould hold that there is an absolute obligation to obey the law when, and only when, obedience is optimific, and 
The second utilitarian argument appeals not to the untoward consequences of individual disobedience, but rather to those of general disobedience. Perhaps the most common challenge to those who defend certain instances of civil disobedience is "What would happen if everyone disobeyed the law?" One of the arguments implicit in this question is the generalization argument, which may be expanded as follows:

No one can have a right to do something unless everyone has a right to do it. Similarly, an act cannot be morally indifferent unless it would be morally indifferent if everyone did it. But, every. one's breaking the law is not a matter of moral indifference; for no government can survive in such a circumstance and, as we have already agreed, government is necessary for securing and maintaining the general good. Hence, since the consequences of general disobedience would be disastrous, each person subject to law has a prima facie obligation to obey it.

In assessing this argument, we must first recognize that the generalization argument is a moral criterion to be applied with care, as virtually everyone who has discussed it has recognized. ${ }^{30}$ If we simply note that if everyone committed a certain act there would be disastrous consequences and thereupon conclude that there is a prima facie obligation not to commit acts of that kind, we will be saddled with absurdities. We will have to maintain, for example, that there is a prima facic obligation not to eat dinner at five o'clock, for if everyone did so, certain essential services could not be maintained. And, for similar reasons, we will have to maintain that there is a prima facie obligation not to produce food. Now, those who believe that the generalization argument is valid argue that such absurdities arise when the criterion is applied to acts which are either too generally described or described in terms of morally irrelevant features. They would argue that the generalization argument appears to go awry when applied to these examples because the description "producing food" is too general to give the argument purchase and because the temporal specification in "eating dinner at five o'clock" is morally irrelevant. ${ }^{31}$

However, such a restriction on the generalization argument is fatal to its use in proving a prima facie obligation to obey the law. This is because a person who denies any such obligation is surely

would there end the discussion. At most, an act utilitarian would hold that the rule "Obey the law" is a useful rule of thumb, to be followed only when the conscquences of obedience or disobedience are difficult to discern.

30. SiNGER, supra note 28 , at ch. 4 .

31. I have borrowed these cases and this strategy for handling them from Singer. Id. at $71-83$. 
entitled to protest that the description "breaking the law" is overly general, on the ground that it refers to acts of radically different moral import. ${ }^{32}$ Breaking the law perhaps always has some bad consequences; but sometimes the good done by it balances the bad or even outweighs it. And, once we take these differences in consequences into account, we find that utilitarian generalization, like weak act-utilitarianism, can only establish a specific prima facie obligation to obey the law when obedience is optimific. Were everyone to break the law when obedience is optimific, the consequences would undoubtedly be disastrous; but it is by no means clear that it would be disastrous if everyone broke the law when obedience is not optimific. Since no one knows, with respect to any society, how often obedience is not optimific, no one can be certain as to the consequences of everyone acting in this way. Indeed, for all we know, if everyone broke the law when obedience was not optimific the good done by separate acts of lawbreaking might more than compensate for any public disorder which might result. In sum, even if the generalization argument is regarded as an acceptable principle of prima facie obligation, the most it demonstrates is that there is a specific prima facie obligation to obey the law whenever the consequences of obedience are optimific.

Some readers-especially those unfamiliar with the recent literature on utilitarianism ${ }^{33}-$ may suspect that this last argument involves sleight of hand. They may object:

In your discussion of the generalization argument, you argued that we have no way of knowing the consequences if everyone disobeyed when obedience was not optimific. But, your argument rests on the premise that the act-utilitarian formula can be perfectly applied, whereas this is in fact impossible: The consequences of many acts are difficult or impossible to foretell; and so, were we all to attempt to be act utilitarians, we would either make horrendous mistakes or be paralyzed into inaction. In constructing a

32. According to Singer, a mark of a description's being overly general is that the generalization argument is "invertible" with respect to it, $i . e$. , the consequences of every: one's doing the act (given that description) is disastrous and the consequences of everyone's failing to do it is also disastrous. Id. at 76-77. It is relesant to note that the gencraliza. tion argument is plainly invertible with respeet to the description "breaking the law." Sometimes breaking the law is the only way to avoid a great evil; and so, if creryone were always to obey the law, such evils could never be avoided.

33. That the generalization argument and weak act utilitarianism offer the same advice on the topic of obedience to the law should surprise no one familiar with $D$. LyoNs, ForMs AND LIMITS OF UTILITARIANisM (1965). Lyours there shows that act utilitarian. ism and the generalization argument are extensionally equivalent. There is, it should be noted, a substantial difference between Lyons' argument for equisalence and the argument $I$ have here offered. Lyons argues for equivalence on a priori grounds, whereas I have relied on the empirical impossibility of determining the consequences of ereryone disobeying the law when obedience is not optimific. 
rule-utilitarian theory of prima facie obligations, we should therefore concentrate not on the consequences of everyone following certain rules, but rather on the consequences of everyone trying to follow them. And, it seems reasonable to believe that, on such a theory, the rule "Obey the law" would receive utilitarian blessing.

As it stands, this objection is overdrawn. My argument does not presuppose that persons can generally succeed in applying the act-utilitarian formula: I merely speculated on the consequences of everyone behaving in a certain way; and I made no assumption as to what made them act that way. Moreover, the objection severely overestimates the difficulty in being a confirmed act-utilitarian. Still, the objection makes one substantial point that deserves further attention. Rule-utilitarian theories which focus on the consequences of everyone accepting (although not always following) a certain set of rules do differ markedly from the generalization argument; and so the question remains as to whether such a theory could establish a prima facie obligation to obey the law. I shall therefore discuss whether the most carefully developed such theory, that given by R. B. Brandt, ${ }^{34}$ does just this.

In Brandt's theory, one's obligations are (within certain limits) relative to his society and are determined by the set of rules whose acceptance in that society would have better consequences than would acceptance of any other set. ${ }^{35}$ According to this theory, then, there can be a generic prima facie obligation to obey the law within a given society if, and only if, general acceptance of the rule "Obey the law," as a rule of prima facie obligation, would have better consequences than were no rule accepted with respect to obeying the law, as well as better consequences than were some alternative rule accepted (e.g., "Obey the law when obedience to the law is optimific," or "Obey the law so long

34. Brandt, Toward a Credible Utilitarianism, in Moraluty and The Language of Conduct 107 (H.N. Costenada \& G. Nakhnikian eds. 1963). In the following I shall not be attacking a position Brandt holds, but only an argument that might be offered on the basis of his theory. In fact, in Utility and the Obligation to Obey the Law, in LAw AND Philosophy 43, 47-49 (S. Hook ed. 1964) Brandt expresses doubt as to whether there is such an obligation.

35. According to Brandt's theory, there is an absolute obligation to perform an act if it conforms with that learnable set of rules the recognition of which as morally binding -roughly at the time of the act-by everyone in the society of the agent, except for the retention by individuals of already formed and decided moral convictions, would maximize intrinsic value.

Brandt, Toward a Credible Utilitarianism, in Morantry and The Language of Conduct 107,139 (H.N. Castenada \& G. Nakhnikian eds. 1963). He distinguishes three levels of rules, the first stating prima facie obligations and the latter two dealing with cases in which lower-level rules conflict. At every level, however, those in the favored set of rules are those whose recognition would have the best consequences, i.e., consequences better than were any alternative rule accepted, as well as better than were no such rule accepted. Id. at 118-19. 
as it is just"). Now, to many it may seem obvious that the ideal set of rules for any society will contain the rule "Obcy the law," on the ground that, were its members not generally convinced of at least a prima facie obligation to obey, disobedience would be widespread, resulting in a great many crimes against person and property. But, there are two reasons to doubt such a gloomy forecast. First, we must surely suppose that in this hypothetical society the laws are still backed by sanctions, thereby giving its members a strong incentive to obey its laws. Second, we must also assume that the members of that society accept other moral rules (e.g., "Do not harm others," "Keep promises," "Tell the truth") which will give them a moral incentive to obey the law in most circumstances. It is, in short, a mistake to believe that unless people are convinced that they have a generic prima facie obligation to obey the law, they cannot be convinced that in most circumstances they have a specific prima facie obligation to obey particular laws. We may therefore expect that, even though members of our hypothetical society do not accept a moral rule about obedience to the law per se, they will still feel a prima facie obligation to act in accordance with the law, save when disobedience does no harm. There is, then, no reason to think that an orgy of lawbreaking would ensue were no rule about obedience to the law generally recognized; nor, I think, is there any good reason to believe that acceptance of the rule "Obey the law" would in any society have better consequences than were no such rule recognized And, if this is so, there is surely no reason to think that recognition of this rule would have better consequences than recognition of some alternative rule. In sum, Brandt's theory requires that we be able to determine the truth-value of a large number of counterfactual propositions about what would happen were entire societies persuaded of the truth of certain moral rules. But, even if we assumeand it is hardly clear that we should ${ }^{30}$-that we can reliably determine the truth-value of such counter-factuals through "common sense" and our knowledge of human nature, Brandt's form of rule utilitarianism gives no support for the proof of a prima facie obligation to obey the law.

\section{IV}

In the foregoing discussion, I have played the skeptic, contending that no argument has as yet succeeded in establishing a prima facie

36. As an illustration of the difficulty, Brandt suggests that the first-level rule "Kecp your promises" is neither the one that we accept nor the rule about promising that would maximize utility. Id. at 131-32. I think he is right to say that it is not the rule we accept, but how does he know that some more complex rulc maximizes utility? 
obligation to obey the law. I want now to examine this supposed obligation directly. I shall assume arguendo that such an obligation exists in order to inquire as to how it compares in moral weight with other prima facie obligations. As we shall see, this question is relevant to whether we should hold that such an obligation exists.

To discuss this question, I must, of course, first specify some test for determining the weight of a prima facie obligation. It will be recalled that I defined "prima facie obligation" in terms of wrongdoing: To say that a person $S$ has a prima facie obligation to do an act $X$ is to say that $S$ has a moral reason to do $X$ which is such that, unless he has a reason not to do $X$ that is at least as strong, $S$ 's failure to do $X$ is wrong. Now, we are accustomed, in our reflective moral practice, to distinguish degrees of wrongdoing. And so, by appealing to this notion, we can formulate two principles that may reasonably be held to govern the weight of prima facie obligations: First, that a prima facie obligation is a serious one if, and only if, an act which violates that obligation and fulfils no other is seriously wrong; and, second, that a prima facie obligation is a serious one if, and only if, violation of it will make considerably worse an act which on other grounds is already wrong.. ${ }^{37}$ These principles, which constitute tests for determining an obligation's weight, are closely related, and application of either to a given prima facie obligation is a sufficient measure; but I shall apply both to the presumed prima facie obligation to obey the law in order to make my argument more persuasive.

First, however, we should convince ourselves of the reliability of these tests by applying them to some clear cases. I suppose it will be granted that we all have a prima facie obliation not to kill (except perhaps in self-defense), and that this obligation is most weighty. Our first test corroborates this, for, if a person kills another when he is not defending himself and if he has no specific prima facie obligation to kill that person, his act is seriously wrong. By contrast, our prima facie obligation to observe rules of etiquette-if indeed there is any such obli-

37. The second principle may be thought objectionable on the ground that it trivializes obviously weighty prima facie obligations. It may perhaps be held that, were a man to kill a thousand persons, his act would not have been much worse had he killed but one more. The principle therefore seems to imply that the prima facic obligation not to kill that one person is trivial. The objection is plausible, but misguided. Surcly there is a substantial moral difference between killing a thousand persons and killing a thousand-and-one-exactly the difference between killing one person and killing nonc. To deny this is to imply that the thousand-and-first person's life has little moral sig. nificance. At first glance, however, we may be inclined to take the difference to be trivial, because both acts are so monstrous that we should rarely sec any point in dis. tinguishing between them. That this objection might be raised against the principle was pointed out to me by Anne Bowen. 
gation-is clearly trifling. This is borne out by our test, for if I belch audibly in the company of those who think such behavior rude, my wrongdoing is at most trivial. The same results are obtained under our second test. If I attempt to extort money from someone my act is much worse if I kill one of his children and threaten the rest than if I merely threatened them all; and so the obligation not to kill again counts as substantial. Similarly, the prima facie obligation to observe the rules of etiquette is again trivial, for if I am rude during the extortion my act is hardly worse than it would have been had I been polite.

By neither of these tests, however, does the prima facie obligation to obey the law count as substantial. As for the first test, let us assume that while driving home at two o'clock in the morning I run a stop sign. There is no danger, for I can see clearly that there was no one approaching the intersection, nor is there any impressionable youth nearby to be inspired to a life of crime by my flouting of the traffic code. Finally, we may assume that I nevertheless had no specific prima facie obligation to run the stop sign. If, then, my prima facie obligation to obey the law is of substantial moral weight, my action must have been a fairly serious instance of wrongdoing. But clearly it was not. If it was wrong at all-and to me this seems dubious-it was at most a mere peccadillo. As for the second test, we may observe that acts which are otherwise wrong are not made more so-if they are made worse at all-by being illegal..$^{38}$ If I defraud someone my act is hardly worse morally by being illegal than it would have been were it protected by some legal loophole. Thus, if there is a prima facie obligation to obey the law, it is at most of trifling weight.

This being so, I suggest that considerations of simplicity indicate that we should ignore the supposed prima facie obligation to obey the law and refuse to count an act wrong merely because it violates some law. There is certainly nothing to be lost by doing this, for we shall not thereby recommend or tolerate any conduct that is seriously wrong, nor shall we fail to recommend any course of action that is seriously obligatory. Yet, there is much to be gained, for in refusing to let trivialities occupy our attention, we shall not be diverted from the important questions to be asked about illegal conduct, viz., "What

38. I have taken this point from 1 W. BLAckstone, Commentaries o54:

Neither do divine or natural duties (such as, for instance, the vorship of God, the maintenance of children, and the like) receive any stronger sanetion from being also declared to be duties by the law of the land. The case is the same as to crimes and misdemeanors, that are forbidden by the superior laws, and therefore styled mala in se, such as murder, theft, and perjury; which contract no additional turpitude from being declared unlawful by the inferior legislature. 
kind of act was it?," "What were its consequences?," "Did the agent intend its consequences?," and so forth. Morality is, after all, a serious business; and we are surely right not to squander our moral attention and concern on matters of little moral significance.

To illustrate what can be gained, let us consider briefly the issue of civil disobedience. Most philosophers who have written on the subject have argued that, at least in democratic societies, there is always a strong moral reason to obey the law. They have therefore held that civil disobedience is a tactic to be employed only when all legal means of changing an unjust law have failed, and that the person who engages in it must willingly accept punishment as a mark of respect for the law and recognition of the seriousness of lawbreaking. However, once we abandon the notion that civil disobedience is morally significant per se, we shall judge it in the same way we judge most other kinds of acts, that is, on the basis of their character and consequences. Indeed, we can then treat civil disobedience just as we regard many other species of illegal conduct. If breaking the law involves an act which is mala in se or if it has untoward consequences, we are ordinarily prepared to condemn it and to think that the malefactor ought to accept punishment. But if lawbreaking does not involve an act that is mala in $s e$ and if it has no harmful consequences, we do not ordinarily condemn it, nor do we think that its perpetrator must accept puinshment, unless evading punishment itself has untoward consequences. If we adopt this view of civil disobedience, we shall have done much to escape the air of mystery that hovers about most discussions of it.

Of course, this is not to say it will be easy to determine when civil disobedience is justified. Some have maintained that the civil disobedience of the last decade has led to increasing violation of laws which safeguard people and property. ${ }^{30}$ If this is true, each instance of disobedience which has contributed to this condition has a share in the evil of the result. Others maintain that such disobedience has had wholly good consequences, that it has helped to remedy existing injustice and to restrain government from fresh injustice. ${ }^{40}$ Still others think its consequences are mixed. Which position is correct is difficult to determine. I myself am inclined to believe that, although the consequences have been mixed, the good far outweigh the bad; but I would be hard pressed to prove it. What is clear, however, is that either abandoning or retaining the supposed prima facie obligation

39. C. Whittaker, First Lecture, in LAw, Order and Civil Disodedience (1967),

40. See H. ZinN, Disobedience AND Democracy (1968). 
to obey the law will not help settle these questions about consequences. But, if we do abandon it, we shall then at least be able to focus on these questions without having to worry about a prima facie obligation of trivial weight that must nevertheless somehow be taken into account. Finally, if we abandon the prima facie obligation to obey the law, we shall perhaps look more closely at the character of acts performed in the course of civil disobedience, and this may, in turn, lead to fruitful moral speculation. For example, we shall be able to distinguish between acts which cannot conceivably violate the obligation of fair play (e.g., burning one's draft card) and acts which may do so (e.g., tax refusal or evasion of military service). This in turn may provide an incentive to reflect further on the obligation of fair play, to ask, for example, whether Rawls is right in his present contention that a person can incur the obligation of fair play only so long as his acceptance of the benefits of a cooperative enterprise is wholly voluntary.

\section{$\mathrm{V}$}

It is now time to take stock. I initially suggested that it is by no means obvious that there is any prima facie obligation to obey the law. In the foregoing, I have rejected a number of arguments that purport to establish its existence. The only plausible argument $I$ have not rejected is the one of Rawls that purports to prove that there is a natural duty to obey the laws of reasonably just governments. However, I did note that his position lacks intuitive support and rests on a controversial ethical theory which has not yet withstood the test of critical scrutiny. Finally, I have shown that even if such an obligation is assumed, it is of trivial weight and that there are substantial advantages in ignoring it. I suggest that all of this makes it reasonable to maintain that there is in no society a prima facie obligation to obey the law.

Before I conclude my discussion, however, I want to tie up one loose thread. Near the beginning of my argument I distinguished the question to be discussed from that which I called the lawyer's question, "May a reasonable man take mere illegality to be sufficient evidence that an act is morally wrong, so long as he lacks specific evidence that tends to show that it is right?" Since I have raised the question, I believe that, for the sake of completeness, I should consider it, if only briefly. To begin, it seems very doubtful that there is, in the lawyer's sense, a prima facie obligation to obey the law. It is undoubtedly true that most instances of lawbreaking are wrong, but it is also true that many are not: This is because there are, as Lord Devlin once remarked, 
"many fussy regulations whose breach it would be pedantic to call immoral," 41 and because some breaches of even non-fussy regulations are justified. Now, unless-as in a court of law-there is some pressing need to reach a finding, the mere fact that most $A$ s are also $B$ does not, in the absence of evidence that a particular $A$ is not $B$, warrant an inference that the $A$ in question is also a $B$ : In order for this inference to be reasonable, one must know that virtually all $A s$ are $B$ s. Since, then, it rarely happens that there is a pressing need to reach a moral finding, and since to know merely that an act is illegal is not to know very much of moral significance about it, it seems clear that, if his only information about an act was that it was illegal, a reasonable man would withhold judgment until he learned more about it. Indeed, this is not only what the fictitious reasonable man would do, it is what we should expect the ordinary person to do. Suppose we were to ask a large number of people: "Jones has broken a law; but I won't tell you whether what he did is a serious crime or merely violation of a parking regulation, nor whether he had good reason for his actions. Would you, merely on the strength of what I have just told you, be willing to say that what he did was morally wrong?" I have conducted only an informal poll; but, on its basis, I would wager that the great majority would answer "I can't yet say-you must tell me more about what Jones did."

More importantly, it appears to make little difference what answer we give to the lawyer's question. While an affirmative answer establishes a rule of inference that an illegal act is wrong in the absence of specific information tending to show it to be right, it is a rule that would in fact virtually never be applied in any reasonable determination of whether an illegal act is wrong. If, on the one hand, we have specific information about an illegal act which tends to show it to be right, then the rule is irrelevant to our determination of the act's moral character. Should we be inclined, in this instance, to hold the act wrong we must have specific information which tends to show this; and it is clear that our conclusions about its moral character must be based on this specific information, and not on the supposed reasonableness of holding illegal conduct wrong in the absence of specific information tending to show it is right. On the other hand, if we have specific information tending to show that an illegal act is wrong and no information tending to show it is right, the rule is applicable but otiose: Since we have ample specific reason to condemn the act, the rule is

41. P. Deviin, The Enforcement of Morals 27 (1965). 
superfluous to our judgment. It would seem, then, that the rule is relevant only when we have no specific information about the illegal conduct's rightness or wrongness; and this, I suggest, is something that virtually never occurs. When we are prompted to make a moral judgment about an illegal act, we virtually always know something of its character or at least its consequences; and it is these that we consider important in determining the rightness or wrongness of lawbreaking. In short, it seems to make little difference what answer we give to the lawyer's question; I raise it here only that it may hereafter be ignored.

In conclusion, it is, I think, important to recognize that there is nothing startling in what I am recommending, nothing that in any way outrages common sense. Even the most conscientious men at times violate trivial and pointless laws for some slight gain in convenience and, when they do so, they do not feel shame or remorse. Similarly, when they observe other men behaving in a like fashion, they do not think of passing moral censure. For most people, violation of the law becomes a matter for moral concern only when it involves an act which is believed to be wrong on grounds apart from its illegality. Hence, anyone who believes that the purpose of normative ethics is to organize and clarify our reflective moral practice should be skeptical of any argument purporting to show that there is a prima facie obligation to obey the law. It is necessary to state this point with care: I am not contending that reflective and conscientious citizens would, if asked, deny that there is a prima facie obligation to obey the law. Indeed, I am willing to concede that many more would affirm its existence than deny it. But, this is in no way inconsistent with my present point. We often find that reflective people will accept general statements which are belied by their actual linguistic practice. That they also accept moral generalizations that are belied by their actual reflective moral practice should occasion no surprise.

This last point may, however, be challenged on the ground that it implies that there is in our reflective moral practice no distinction between raw power and legitimate authority. As I noted above, the concept of legitimate authority is often analyzed in terms of the right to command, where "right" is used in the strict sense as implying some correlative obligation of obedience. Given this definition, if it is true that the principle "There is a prima facie obligation to obey the law" is not observed in our reflective moral practice, it follows that we do not really distinguish between governments which possess legitimnte authority (e.g., that of the United States) and those which do not (e.g., the Nazi occupation government of France). And this, it may justly be 
held, is absurd. What I take this argument to show, however, is not that the principle is enshrined in our reflective morality, but rather that what we ordinarily mean when we ascribe legitimate authority to some government is not captured by the usual analysis of "legitimate authority." It is a mistake to believe that, unless we employ the concept of authority as it is usually analyzed, we cannot satisfactorily distinguish between the moral relation of the government of the United States vis-à-vis Americans and the moral relation of the Nazi occupation government vis-à-vis Frenchmen. One way of doing this, for example, is to define "legitimate authority" in terms of "the right to command and to enforce obedience," where "right" is used in the sense of "what is morally permissible." Thus, according to this analysis of the notion, the government of the United States counts as having legitimate authority over its subjects because within certain limits there is nothing wrong in its issuing commands to them and enforcing their obedience, whereas the Nazi occupation government lacked such authority because its issuing commands to Frenchmen was morally impermissible. It is not my intention to proffer this as an adequate analysis of the notion of legitimate authority or to suggest that it captures what we ordinarily mean when we ascribe such authority to some government. These are difficult matters, and I do not wish to address myself to them here. My point is rather that the questions "What governments enjoy legitimate authority?" and "Have the citizens of any government a prima facie obligation to obey the law?" both can be, and should be, kept separate. 